\title{
Supressividade dos nematóides Meloydogine javanica e Heterodera glycines em soja por adição de lodo de esgoto ao solo
}

\author{
Supressiveness of nematodes Meloydogine javanica e Heterodera glycines in soybean by \\ sewage sludge incorporated in the soil
}

\author{
Fabio Fernando de Araújo ${ }^{1}$ Wagner Bettiol ${ }^{2}$
}

\section{RESUMO}

O lodo de esgoto, atendendo às exigências ambientais, apresenta grande potencial para utilização em solos agrícolas, onde vem sendo amplamente disposto. Sua utilização altera propriedades químicas, físicas e biológicas do solo, devido a sua composição em macro e micronutrientes e matéria orgânica. Estas alterações podem proporcionar benefícios como aumento da disponibilidade nutricional às culturas, indução de supressividade aos fitopatógenos presentes no solo e resistência às doenças da parte aérea. Por outro lado, pode influenciar negativamente o equilíbrio biológico e químico no solo, devido à presença de concentrações consideráveis de $N$ disponível, sais solúveis e metais pesados. Com o objetivo de avaliar os efeitos da incorporação de lodo de esgoto ao solo sobre supressividade de nematoides de galha (Meloydogine javanica (Treub) Chitwood) e do cisto (Hetodera glycines Ichinoe), parasitas da soja (Glycine max L.), foram realizados experimentos em laboratório e casa de vegetação utilizando-se solo coletado de área experimental da Embrapa Meio Ambiente, Jaguariúna, SP. Esta área recebeu aplicações sucessivas de lodos de esgotos, originários das Estações de Tratamento de Esgoto de Barueri e de Franca, no Estado de S. Paulo, durante cinco anos (1998-2002). Com relação à indução de supressividade a nematóides, observou-se que o lodo de esgoto não afetou o desenvolvimento de fêmeas de $\boldsymbol{H}$. glycines no solo (apenas reduziu o número de ovos por cisto) contudo reduziu a reprodução de $\boldsymbol{M}$. javanica, nas raízes de soja.

Palavras-chave: controle de doenças, atividade microbiana, metais pesados, nutrição vegetal.

\section{ABSTRACT}

Sewage sludge has shown great potential for use in agriculture, where it has been widely used. There are some modifications on chemical, physical and biological properties of the soil due to its composition of macro and micronutrients and organic substances. These alterations can provide benefits as an increase to the availability of nutrients to the plants, suppressiveness induction of soilborne plant pathogens and resistance to foliar diseases. However, it may influence negatively the biological and chemical balance in the soil, due to the presence of considerable amounts of available $N$, soluble salts and heavy metals. The aim of this work was to evaluate the effect of sewage sludge incorporation to the soil and the suppressiveness induction of nematodes (Meloydogine javanica (Treub) Chitwood and Heterodera glycines Ichinoe) in soybean (Glycine max L.). Experiments were performed in laboratory and in a greenhouse using collected soil in an experimental area of the Embrapa Meio Ambiente, Jaguariúna, $S P$. This area received successive applications of sewage sludge, originary from the sewage treatment of Barueri and Franca, in São Paulo State, Brazil, during five years (19982002). In relation to the suppressiveness induction of nematodes, the sludge did not affect significantly the development of $\boldsymbol{H}$. glycines in the soil, but reduced the $\boldsymbol{M}$. javanica reproduction, in the soybean root.

Key words: disease control, heavy metals, microbial activity, plant nutrition.

\section{INTRODUÇÃO}

A utilização do lodo de esgoto na agricultura vem crescendo a cada ano em vários países (LUMSDEM et al., 1983; WANG, 1997). As características principais do lodo depende do processo adotado em cada estação de tratamento de esgoto. Dentre elas, as características químicas do lodo tem sido o grande foco para análise de impacto ambiental no solo, de acordo com as exigências ambientais

${ }^{1}$ Engenheiro Agrônomo, Doutor, Professor do curso de Agronomia, Universidade do Oeste Paulista, Rodovia Raposo Tavares, Km 572, 19067-175, Presidente Prudente, SP, Brasil. E-mail fabio@unoeste.br. Autor para Correspondência. Parte da tese de Doutorado. ${ }^{2}$ Engenheiro Agrônomo, Doutor, Pesquisador da Embrapa Meio ambiente, CP 69, 13820-000, Jaguariúna, SP, Brasil. 
(CETESB, 1999) com ênfase principalmente aos metais pesados. Estes elementos têm sua origem nos esgotos sanitários que são compostos de esgotos domésticos, esgoto industrial e água de infiltração. A tecnologia empregada no tratamento do lodo não consegue remover os metais pesados, desta forma eles retornam ao ambiente pela disposição final (WANG, 1997).

Atualmente, a incorporação de lodo de esgoto, como fonte de matéria orgânica no solo, oriundo de processos de compostagem ou digestão anaeróbia, apresenta-se como de grande importância para a indução de supressividade a doenças em solos (LUMSDEN et al., 1983; ZHANG et al., 1996; HOITINK et al., 1997). As primeiras citações envolvendo lodo de esgoto para o controle de fitopatógenos são de COOK et al. (1964) e MULLER \& GOOCH (1982). A partir destas citações, outros trabalhos nesta área foram desenvolvidos. O resíduo orgânico obtido da compostagem do lixo urbano pode aumentar a atividade de antagonistas aos nematóides, formadores de galhas em raízes (McSORLEY \& GALLAHER, 1995). Outros relatos demonstraram que solos que receberam matéria orgânica compostada ou resíduos orgânicos controlaram importantes patógenos de solo (CHEN et al., 1988; HOITINK et al., 1991; KIM et al., 1997; VELAZCO, 2002)

Em função da grande importância econômica do controle de nematóides na cultura da soja do potencial que representa o lodo de esgoto como fornecedor de matéria orgânica e nutrientes ao solo e, no intuito de fornecer subsídios para utilização deste resíduo no controle de parasitas, foi desenvolvido o presente trabalho para avaliação do efeito do lodo de esgoto na indução de supressividade aos nematóides M. javanica e H. glycines em soja.

\section{MATERIAL E MÉTODOS}

Os experimentos foram conduzidos no laboratório de fitopatologia e casa-de-vegetação da Universidade do Oeste Paulista - UNOESTE (Presidente Prudente, SP) e Embrapa Soja (Londrina, PR). O solo foi Latossolo Vermelho Escuro distrófico, proveniente de coleta em 2002 e 2003, da área experimental da Embrapa Meio Ambiente, Jaguariúna, SP. Nesta área, foi incorporado lodo de esgoto, em cinco aplicações anuais (1998 - 2002), em diferentes concentrações, proveniente das Estações de Tratamento de Esgoto (ETE), da SABESP de Franca e de Barueri, SP. O lodo da ETE de Franca é de origem residencial, com baixos teores de metais pesados. $\mathrm{O}$ lodo proveniente da ETE de Barueri (Região metropolitana de S. Paulo) tem grande representatividade de lançamentos industriais sobre as vazões de origem residencial, desta forma apresenta concentrações maiores de metais pesados (Tabela 1). Os lodos provenientes das ETE's citadas são considerados como lodo ativado convencional, condicionado com polímero catiônico e desaguado.

Os lodos provenientes das ETE's (Franca e Barueri) foram incorporados anualmente ao solo da área experimental da Embrapa Meio Ambiente, incorporado com enxada rotativa tracionada por trator. As parcelas, no total de 36, foram estabelecidas com a dimensão $10 \mathrm{~m} \times 20 \mathrm{~m}$, sendo a distância entre as parcelas e blocos de $5 \mathrm{~m}$. Para cálculo da taxa de aplicação do lodo, utilizou-se a necessidade de nitrogênio para cultura do milho $\left(90 \mathrm{~kg} \mathrm{ha}^{-1}\right.$ de N) a qual foi implantada no local. O cálculo do nitrogênio

Tabela 1 - Características químicas dos lodos de esgotos das Estações de Tratamento de Esgoto de Franca e Barueri, localizadas no estado de São Paulo.

\begin{tabular}{|c|c|c|c|}
\hline Atributo & Unidade $^{(1)}$ & $\begin{array}{c}\text { Lodo } \\
\text { Barueri }\end{array}$ & $\begin{array}{l}\text { Lodo } \\
\text { Franca }\end{array}$ \\
\hline Fósforo & $\mathrm{g} \mathrm{kg}^{-1}$ & 17,7 & 13,8 \\
\hline Potássio & $\mathrm{g} \mathrm{kg}^{-1}$ & 1,5 & 1,5 \\
\hline Sódio & $\mathrm{g} \mathrm{kg}^{-1}$ & 0,5 & 0,5 \\
\hline Arsênio & $\mathrm{mg} \mathrm{kg}^{-1}$ & $<0,01$ & $<0,01$ \\
\hline Cádmio & $\mathrm{mg} \mathrm{kg}^{-1}$ & 16,2 & 1,14 \\
\hline Chumbo & $\mathrm{mg} \mathrm{kg}^{-1}$ & 137,9 & 78,6 \\
\hline Cobre & $\mathrm{mg} \mathrm{kg}^{-1}$ & 682,8 & 187,1 \\
\hline Cromo total & $\mathrm{mg} \mathrm{kg}^{-1}$ & 609,3 & 202,0 \\
\hline Mercúrio & $\mathrm{mg} \mathrm{kg}^{-1}$ & $<0,01$ & $<0,01$ \\
\hline Molibdênio & $\mathrm{mg} \mathrm{kg}^{-1}$ & $<0,01$ & $<0,01$ \\
\hline Níquel & $\mathrm{mg} \mathrm{kg}^{-1}$ & 331,3 & 63,9 \\
\hline Selênio & $\mathrm{mg} \mathrm{kg}^{-1}$ & $<0,01$ & $<0,01$ \\
\hline Zinco & $\mathrm{mg} \mathrm{kg}^{-1}$ & 2327,9 & 773,0 \\
\hline Boro & $\mathrm{mg} \mathrm{kg}^{-1}$ & 10,7 & 10,4 \\
\hline Carbono orgânico & $\mathrm{g} \mathrm{kg}^{-1}$ & 354,2 & 370,9 \\
\hline $\mathrm{pH}$ & & 8,5 & 8,9 \\
\hline Umidade & $\%$ & 77,3 & 81,4 \\
\hline Sólidos Voláteis & $\%$ & 62,6 & 67,0 \\
\hline Nitrogênio Kjeldahl & $\mathrm{g} \mathrm{kg}^{-1}$ & 44,6 & 47,4 \\
\hline Nitrogênio- amoniacal & $\mathrm{mg} \mathrm{kg}^{-1(2)}$ & 2094,8 & 2330,6 \\
\hline Nitrogênio- Nitrato-nitrito & $\mathrm{mg} \mathrm{kg}^{-1(2)}$ & 15,4 & 56,4 \\
\hline Enxofre & $\mathrm{g} \mathrm{kg}^{-1}$ & 11,7 & 9,3 \\
\hline Manganês & $\mathrm{mg} \mathrm{kg}^{-1}$ & 277,5 & 439,8 \\
\hline Ferro & $\mathrm{mg} \mathrm{kg}^{-1}$ & 39058 & 39895 \\
\hline Magnésio & $\mathrm{g} \mathrm{kg}^{-1}$ & 3,7 & 2,7 \\
\hline Alumínio & $\mathrm{mg} \mathrm{kg}^{-1}$ & 11959 & 18189 \\
\hline Cálcio & $\mathrm{g} \mathrm{kg}^{-1}$ & 20,1 & 13,3 \\
\hline
\end{tabular}

${ }^{(1)}$ Os valores de concentração são dados com base na matéria seca.

${ }^{(2)}$ Os valores de concentração para o nitrogênio nas formas amoniacal e nitrato foram determinados na amostra nas condições originais. 
a ser aplicado, utilizando o lodo de esgoto, foi fundamentado no nitrogênio disponível para as plantas considerando a taxa de mineralização de $40 \%$, ou seja, do $\mathrm{N}$ total do resíduo considera-se que apenas $40 \%$ vai estar disponível às plantas. Com base nesta necessidade, foram definidas concentrações com uma, duas, quatro e oito vezes a quantidade de $\mathrm{N}$ necessária à cultura, estabelecendo-se os seguintes tratamentos com três repetições: Lodo de esgoto de Franca - F1N: aplicação de 4,4t do resíduo/ha para fornecer $90 \mathrm{~kg}$ de $\mathrm{N}$; F2N: aplicação de $8,8 \mathrm{t}$ do resíduo ha-1 ${ }^{-1}$ para fornecer 180kg de N; F4N: aplicação de 17,6t do resíduo ha ${ }^{-1}$ para fornecer $360 \mathrm{~kg}$ de $\mathrm{N}$ e F8N: aplicação de 35,4t do resíduo ha-1 para fornecer $720 \mathrm{~kg}$ de $\mathrm{N}$. Lodo de esgoto de Barueri - B1N: aplicação de 5,3t do resíduo ha ${ }^{-1}$ para fornecer $90 \mathrm{~kg}$ de N; B2N: aplicação de 10,6t do resíduo ha $^{-1}$ para fornecer $180 \mathrm{~kg}$ de N; B4N: 21,2 t do resíduo $\mathrm{ha}^{-1}$ para fornecer $360 \mathrm{~kg}$ de N e B8N: aplicação de 42,4t do resíduo ha ${ }^{-1}$ para fornecer $720 \mathrm{~kg}$ de N. Foram conduzidas também testemunhas absolutas (TAB) e relativas (adubação mineral NPK).

Para instalação dos experimentos com soja, em vasos, foram coletados amostras de solo em duas épocas distintas. A primeira coleta no mês de março (2002), após a quarta aplicação (2001) de lodo na área experimental e a segunda em março (2003), após a quinta aplicação (2002) do lodo. As amostras de solo pesando, em média $10 \mathrm{~kg}$, foram retiradas de cinco pontos aleatórios, na profundidade de $0-20 \mathrm{~cm}$, de cada parcela do experimento descrito anteriormente. As mesmas foram homogeneizadas, deixadas secar por 24 horas na sombra, e posteriormente o solo foi distribuído em vasos plásticos ( $2 \mathrm{~kg}$ de solo) para realização dos experimentos propostos.

Experimento com Heterodera glycines Foi realizado um experimento em 2002 com este nematóide, onde sementes de soja (cultivar BRS 133) foram semeadas no solo acondicionado nos vasos, coletado da área experimental, conforme descrito anteriormente. Para infestação dos vasos, foram coletados cistos de $\boldsymbol{H}$. glycines, raça 3, multiplicados em vasos com soja durante três meses. Para obtenção do inóculo, as raízes de soja foram lavadas em água corrente sobre uma peneira com abertura de 60 mesh. Os cistos retidos na peneira foram cuidadosamente transferidos para uma placa de Petri onde foram selecionados pela cor e tamanho, com auxílio de microscópio estereoscópico. Para infestação, foram utilizados 20 cistos por vaso, os quais foram introduzidos no solo através de orifício central $(0,5$ $\mathrm{cm}$ de diâmetro) na superfície, com $1 \mathrm{~cm}$ de profundidade. $\mathrm{O}$ experimento foi instalado em casa de vegetação da Embrapa Soja (Londrina, PR) e conduzido durante 62 dias (março a maio de 2002). Após este período as plantas foram coletadas retirando-se com cuidado as raízes do solo, as mesmas foram separadas da parte aérea e lavadas sob jato forte de água sobre conjunto de peneiras na sequiência de 20, 100 e 500 mesh (aberturas de 840, 149 e 26mm). Os cistos retidos na peneira de 100 mesh foram contados e, em seguida, esmagados na própria peneira, com auxílio de um tubo de ensaio e os ovos retidos na peneira 500 mesh foram recolhidos em solução de sacarose (454g L $\mathrm{g}^{-1}$ de água). As suspensões foram centrifugadas a $800 \mathrm{~g}$ por um minuto e o sobrenadante vertido em peneira de 500 mesh, a suspensão foi então recolhida em becker de $50 \mathrm{~mL}$ e determinada a concentração de ovos com o auxílio da câmara de Peters (DIAS et al., 1998). A parte aérea das plantas, separada anteriormente, foi secada até manutenção de peso constante para determinação da massa seca.

Experimento com Meloydogine javanicaForam conduzidos dois experimentos em casa de vegetação da UNOESTE, Presidente Prudente, SP, utilizando-se os solos coletados na área experimental em 2002 e 2003. Sementes de soja da cultivar BRS 133, susceptível a $\boldsymbol{M}$. javanica, foram semeadas no solo coletado acondicionado em vasos plásticos $(2 \mathrm{~kg})$. Em seguida, os vasos foram infestados com 5000 ovos de $\boldsymbol{M}$. javanica multiplicados em raiz de tomate. A extração dos ovos seguiu metodologia descrita por DIAS et al. (1998) sendo iniciada com a lavagem da raiz de tomate e posterior trituração em liqüidificador contendo solução de hipoclorito de sódio (2\%) durante 30 segundos. Em seguida, a raiz triturada foi passada em peneira de 100 e 500 mesh (aberturas de 149 e 26 $\mathrm{mm}$, respectivamente) e o material retido na última peneira foi avaliado em Câmara de Peters, sob microscópio óptico, para contagem de ovos de $\boldsymbol{M}$. javanica. Após a contagem, foi padronizado o uso de 5000 ovos por vaso nos experimentos. A condução dos experimentos, sob condição ambiente, foi por 55 dias após a semeadura. Decorrido este período, as plantas, duas por vaso, foram coletadas com cuidado separando-se a parte aérea das raízes. A parte aérea foi secada para determinação de massa seca. As raízes foram deixadas secar em temperatura ambiente por 12 horas, sobre papel absorvente. Decorrido este período, as mesmas foram pesadas e trituradas em liquidificador. A extração de ovos foi realizada conforme metodologia descrita anteriormente, com avaliação da presença de ovos e juvenis de Meloidogyne javanica. Para avaliação final, foram realizadas cinco amostragens, de $1 \mathrm{~mL}$ cada, no material retido na peneira, para cada parcela, sendo a contagem efetuada em microscópio óptico (100x). O 
resultado final foi expresso com a divisão da média, das cinco contagens, pelo peso da raiz, encontrandose desta forma o número de ovos e juvenis por g de raiz. Também foi obtido o fator de reprodução (FR) dividindo-se o total de ovos encontrados nas raízes pelo inóculo inicial.

O delineamento experimental utilizado foi inteiramente casualizado, sendo cada parcela do experimento original (Embrapa Meio Ambiente, Jaguariúna, SP) subdividida em duas, totalizando no final seis repetições. A análise estatística foi efetuada utilizando-se o programa SANEST aplicando-se o teste de Tukey $(\mathrm{p}<0,05)$ para comparação de médias.

\section{RESULTADOS E DISCUSSÃO}

A incorporação de lodo não proporcionou redução na incidência de cistos nas raízes de soja, avaliada após dois meses de semeadura da soja, em solo infestado com o parasita (Tabela 2). Entretanto, nos solos que receberam as doses mais elevadas de lodo $(4 \mathrm{~N}$ e $8 \mathrm{~N})$, houve redução nas quantidades de ovos nos cistos, quando comparados às testemunhas,

Tabela 2 - Efeito de lodos de esgotos, originários das ETE de Franca e de Barueri, sobre a recuperação de cistos e ovos do nematóide do cisto da soja (Heterodera glycines) em soja cultivada durante 62 dias, em casa de vegetação no ano de 2002.

\begin{tabular}{lccc}
\hline Tratamentos $^{1}$ & $\begin{array}{c}\mathrm{N}^{\mathrm{o}} \text { de cistos } \\
\left(100 \mathrm{~cm}^{3} \text { de solo }\right)\end{array}$ & $\begin{array}{c}\mathrm{N}^{\mathrm{o}} \mathrm{de} \\
\text { ovos/cisto }\end{array}$ & $\begin{array}{c}\text { Matéria seca da } \\
\text { parte aérea }(\mathrm{g})\end{array}$ \\
\hline FTAB & $7,97 \mathrm{a}^{2}$ & $247 \mathrm{a}$ & $1,25 \mathrm{cde}$ \\
FNPK & $8,47 \mathrm{a}$ & $237 \mathrm{a}$ & $1,21 \mathrm{cde}$ \\
F1N & $9,07 \mathrm{a}$ & $238 \mathrm{a}$ & $2,61 \mathrm{ab}$ \\
F2N & $5,76 \mathrm{a}$ & $220 \mathrm{ab}$ & $1,96 \mathrm{bcde}$ \\
F4N & $6,04 \mathrm{a}$ & $176 \mathrm{~cd}$ & $1,60 \mathrm{bcde}$ \\
F8N & $9,12 \mathrm{a}$ & $175 \mathrm{~cd}$ & $2,73 \mathrm{ab}$ \\
& & & \\
BTAB & $7,81 \mathrm{a}$ & $223 \mathrm{ab}$ & $1,18 \mathrm{de}$ \\
BNPK & $9,31 \mathrm{a}$ & $233 \mathrm{a}$ & $1,03 \mathrm{e}$ \\
B1N & $9,85 \mathrm{a}$ & $223 \mathrm{ab}$ & $2,34 \mathrm{abc}$ \\
B2N & $4,85 \mathrm{a}$ & $198 \mathrm{bc}$ & $3,01 \mathrm{ab}$ \\
B4N & $6,17 \mathrm{a}$ & $179 \mathrm{~cd}$ & $2,62 \mathrm{ab}$ \\
B8N & $9,84 \mathrm{a}$ & $168 \mathrm{~d}$ & $3,50 \mathrm{a}$ \\
CV $(\%)$ & 18,1 & 8,03 & 35,2 \\
\hline
\end{tabular}

${ }^{1} \mathrm{~F}=$ Lodo de esgoto da Estação de tratamento de Esgoto (ETE) de Franca, SP. B= Lodo de esgoto da ETE Barueri, SP. TAB= Testemunha absoluta; NPK= adubação mineral recomendada; $1 \mathrm{~N}$, $2 \mathrm{~N}, 4 \mathrm{~N}$ e $8 \mathrm{~N}=$ doses de lodo necessárias para fornecer uma, duas, quatro e oito vezes a quantidade de $\mathrm{N}$ recomendada para a cultura. ${ }_{2}$ Médias seguidas da mesma letra, na coluna, não diferem significativamente pelo Teste de Tukey ao nível de $5 \%$ de probabilidade. indicando provável efeito supressivo do lodo sobre a reprodução do nematóide nestas condições. Estes resultados são coincidentes com os obtidos por WESTPHAL \& BECKER (2001) que concluíram que os ovos dentro do cisto foram os maiores alvos da supressividade do solo ao nematóide Heterodera schachtii. Este efeito pode ser explicado pelo fato de que a introdução de compostos ou resíduos orgânicos pode estimular a atividade de antagonistas biológicos do nematóide no solo (Mc SORLEY; GALLAHER, 1995). O parasitismo de fungos freqüentemente aumenta quando o cisto do nematóide está maduro (GINTIS et al., 1983). O lodo de esgoto estimula a atividade microbiana no solo (VELAZCO, 2002), o que pode ter contribuído para o aumento do parasitismo sobre ovos do nematóide, nos tratamentos que receberam o resíduo orgânico. CHEN et al. (1994) concluíram que os fungos que colonizam os cistos são tipicamente oportunistas e são afetados severamente pelas condições ambientais, desta forma a adição de resíduos ou manipulação da microflora do solo para controlar o nematóide do cisto da soja precisa de investigações posteriores.

O desenvolvimento do nematóide de galha (M. javanica) em soja foi afetado pela incorporação de lodo de esgoto ao solo. No primeiro experimento, conduzido em 2002, as testemunhas absolutas apresentaram valores reduzidos de recuperação de ovos e juvenis das raízes o que não ocorreu com as testemunhas relativas (NPK) que apresentaram valores elevados de recuperação nesta avaliação (Tabela 3). Os tratamentos que receberam as concentrações de lodo 2N, de ambos locais de origem (Franca e Barueri), apresentaram os menores índices de recuperação de juvenis de $\boldsymbol{M}$.javanica nas raízes. Os tratamentos que receberam a maior dosagem de lodo no solo (F8N e B8N) apresentaram desenvolvimento da planta significativamente superior, porém apenas o tratamento F8N apresentou redução do número de nematóides nas raízes. O fator de reprodução de $\boldsymbol{M}$. javanica foi reduzido nos tratamentos que receberam o lodo na concentração $4 \mathrm{~N}$ de ambos locais de origem (Figura 1). Os mesmos proporcionaram desenvolvimento da soja semelhante aos tratamentos que receberam o dobro da quantidade de lodo (8N) no solo (Tabela 2).

No segundo experimento (2003), com $\boldsymbol{M}$. javanica em solo que recebeu o lodo de esgoto, verificou-se que, entre os tratamentos que receberam lodo de Franca, apenas o F4N apresentou redução na recuperação de ovos das raízes e fator de reprodução do nematóide (Tabela 3). Nos tratamentos que receberam o lodo de esgoto de Barueri apenas o 
Tabela 3 - Efeito de lodo de esgoto, originário da ETE de Franca e de Barueri, sobre a recuperação de ovos e juvenis do nematóide de galha (Meloidogyne javanica) em soja cultivada durante 62 dias, em casa de vegetação nos anos de 2002 e 2003.

\begin{tabular}{|c|c|c|c|c|c|c|}
\hline \multirow[t]{2}{*}{ Tratamentos $^{1}$} & \multicolumn{2}{|c|}{$\begin{array}{c}\text { №-de Juvenis/g } \\
\text { de raiz }\end{array}$} & \multicolumn{2}{|c|}{$\begin{array}{c}\mathrm{N}-\mathrm{O} \text { de ovos/g de } \\
\text { raiz }\end{array}$} & \multicolumn{2}{|c|}{$\begin{array}{l}\text { Matéria seca da } \\
\text { parte aérea }(\mathrm{g})\end{array}$} \\
\hline & 2002 & 2003 & 2002 & 2003 & 2002 & 2003 \\
\hline$\overline{\text { FTAB }}$ & $166 \mathrm{de}^{2}$ & $355 a$ & $1117 \mathrm{~d}$ & $543 a b c$ & $2,68 \mathrm{e}$ & $2,20 \mathrm{e}$ \\
\hline FNPK & 2217 a & $330 a$ & $7189 \mathrm{ab}$ & $1065 \mathrm{a}$ & $2,93 \mathrm{de}$ & $2,96 \mathrm{de}$ \\
\hline F1N & $1778 \mathrm{ab}$ & $210 \mathrm{a}$ & $10580 \mathrm{a}$ & $579 a b c$ & $4,49 \mathrm{~cd}$ & 3,26 cde \\
\hline $\mathrm{F} 2 \mathrm{~N}$ & 136 de & $558 \mathrm{a}$ & $1286 \mathrm{~cd}$ & $558 \mathrm{abc}$ & $5,03 \mathrm{c}$ & $4,75 \mathrm{ab}$ \\
\hline F4N & 407 cde & $388 \mathrm{a}$ & $798 \mathrm{~d}$ & $84 \mathrm{c}$ & $7,13 \mathrm{ab}$ & $5,48 \mathrm{a}$ \\
\hline F8N & $161 \mathrm{de}$ & $473 \mathrm{a}$ & $1066 \mathrm{~d}$ & $681 \mathrm{abc}$ & $7,04 \mathrm{ab}$ & $4,68 \mathrm{abc}$ \\
\hline BTAB & 634 ed & $453 \mathrm{a}$ & $1782 \mathrm{~d}$ & $852 \mathrm{ab}$ & $2,11 \mathrm{e}$ & $2,75 \mathrm{e}$ \\
\hline BNPK & $1441 \mathrm{ab}$ & $463 \mathrm{a}$ & $4852 \mathrm{abc}$ & $380 \mathrm{abc}$ & $3,23 \mathrm{de}$ & $3,13 \mathrm{de}$ \\
\hline $\mathrm{B} 1 \mathrm{~N}$ & $1028 \mathrm{abc}$ & $305 \mathrm{a}$ & $1011 \mathrm{~d}$ & $162 \mathrm{c}$ & $4,57 \mathrm{~cd}$ & 4,41 abcd \\
\hline $\mathrm{B} 2 \mathrm{~N}$ & 88 e & $338 \mathrm{a}$ & $990 \mathrm{~d}$ & $369 \mathrm{abc}$ & $5,94 \mathrm{bc}$ & 3,63 bcde \\
\hline B4N & $860 \mathrm{bc}$ & $453 \mathrm{a}$ & $1016 \mathrm{~d}$ & $285 \mathrm{abc}$ & $6,78 \mathrm{ab}$ & $5,13 \mathrm{a}$ \\
\hline B8N & 425 cde & $302 \mathrm{a}$ & $2277 \mathrm{~cd}$ & $387 \mathrm{abc}$ & $7,70 \mathrm{a}$ & 4,38 abcd \\
\hline C.V.(\%) & 32,4 & 15,70 & 35,6 & 26,70 & 16,9 & 18,75 \\
\hline
\end{tabular}

${ }^{1} \mathrm{~F}=$ Lodo de esgoto da Estação de tratamento de Esgoto (ETE) de Franca, SP. $\mathrm{B}=$ Lodo de esgoto da ETE Barueri, SP. TAB= Testemunha absoluta; NPK= adubação mineral recomendada; $1 \mathrm{~N}, 2 \mathrm{~N}$, $4 \mathrm{~N}$ e $8 \mathrm{~N}=$ doses de lodo necessárias para fornecer uma, duas, quatro e oito vezes a quantidade de $\mathrm{N}$ recomendada para a cultura.

2 Médias seguidas da mesma letra, na coluna, não diferem significativamente pelo Teste de Tukey ao nível de $5 \%$ de probabilidade

tratamento $\mathrm{B} 1 \mathrm{~N}$ apresentou redução na reprodução do nematóide. Os tratamentos B2N, B4N E B8N apresentaram fatores de reprodução maiores que $\mathrm{O}$ tratamento BNPK. Nos tratamentos que receberam o lodo de Franca todos os tratamentos apresentaram valores menores que o tratamento FNPK (Figura 2)

O efeito da adição do lodo ao solo sobre o nematóide de galhas (M.javanica) foi mais consistente do que sobre o nematóide do cisto. Este efeito foi representado principalmente, por reduções pronunciadas no fator de reprodução, mesmo nos tratamentos que receberam as menores concentrações de lodo no solo (Tabela 3). Esta ação pode ter sido provocada pela presença de antagonistas no solo, que estimulados pela presença de matéria orgânica tenham interferido na eclosão e orientação das larvas, além de parasitarem os ovos do nematóide. Sobre esta afirmação, ARAUJO et al. (2002) concluíram que Bacillus subtilis, antagonista do solo, pode interferir no ciclo do nematóide dificultando seu desenvolvimento. CHEN et al. (2000) citaram que a aplicação de composto de cervejaria reduziu a severidade de galhas nas raízes e produção de ovos de $\boldsymbol{M}$. hapla. Sabe-se que o ovo pode ser considerado o estágio mais vulnerável no ciclo de vida de Meloidogyne spp. (VIAENE; ABAWI, 1998).

Alguns autores afirmam que a presença do íon $\mathrm{NH}_{4}{ }^{+}$no solo pode proporcionar efeito nematicida (PEREIRA et al., 1996; RODRIGUES - KABANA, 1986). No caso lodo de esgoto, o $\mathrm{N}-\mathrm{NH}_{4}^{+}$foi a forma predominante de $\mathrm{N}$ mineral no sistemas lodo-solo nas primeiras semanas, em seguida esta forma diminuiu no solo sendo acompanhado de aumento correspondente de $\mathrm{N}-\left(\mathrm{NO}_{3}{ }^{-}+\mathrm{NO}_{2}{ }^{-}\right)$(BOEIRA et al., 2002). Como os experimentos com soja foram realizados alguns meses após a aplicação do lodo no solo, a presença do $\mathrm{N}$ amoniacal deve ter contribuído pouco para o efeito nematicida. A concentração de lodo utilizada no solo, nos dois experimentos, foi importante para definir a melhor estratégia para o controle do nematóide. Os tratamentos com lodo de esgoto de Barueri (1N e 4N) e Franca (4N) mostraramse com maior potencial para incrementos de fatores no solo que influenciaram, negativamente, o desenvolvimento do nematóide nas duas avaliações anuais efetuadas (Tabelas 3).

A presença de rizobactérias promotoras de crescimento de plantas (RPCP), no solo, é um fator importante para controle de nematóides, pois além de seus efeitos diretos sobre o parasita, as mesmas, segundo CHEN et al. (2000), podem mediar a resistência sistêmica induzida (RSI). A

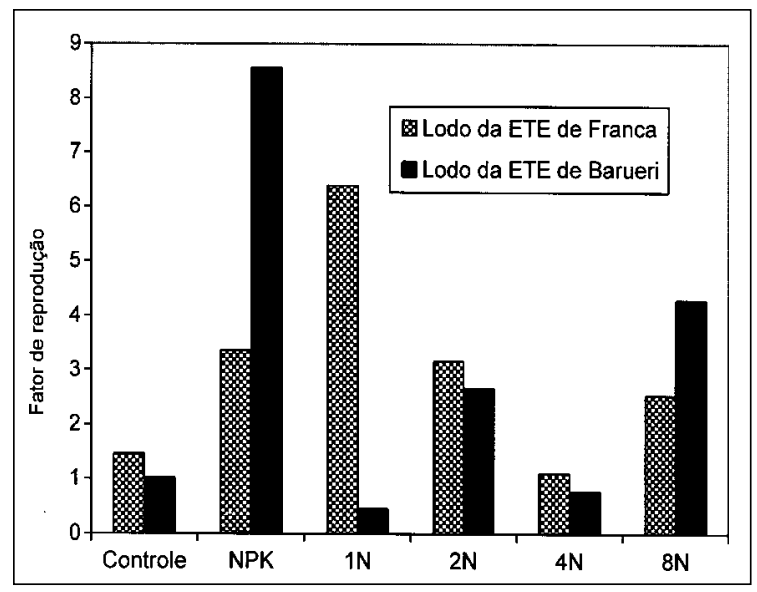

Figura 1 - Fator de reprodução de Meloidogyne javanica em soja cultivada em solo que recebeu diferentes concentrações de lodo de esgoto provenientes das ETEs de Franca e de Barueri. As doses de lodo são necessárias para fornecer uma $(1 \mathrm{~N})$, duas $(2 \mathrm{~N})$, quatro $(4 \mathrm{~N})$ e oito $(8 \mathrm{~N})$ vezes a quantidade de $\mathrm{N}$ da adubação mineral. NPK= adubação mineral recomendada. Experimento conduzido durante 62 dias em casa de vegetação no ano de 2002.

Ciência Rural, v.35, n.4, jul-ago, 2005. 


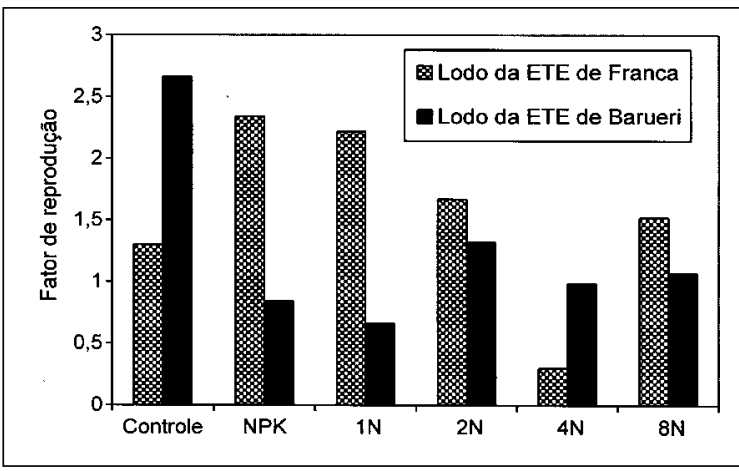

Figura 2 - Fator de reprodução de Meloidogyne javanica em soja cultivada em solo que recebeu diferentes concentrações de lodos de esgoto provenientes das ETEs de Franca e de Barueri. As doses de lodo são necessárias para fornecer uma $(1 \mathrm{~N})$, duas $(2 \mathrm{~N})$, quatro $(4 \mathrm{~N})$ e oito $(8 \mathrm{~N})$ vezes a quantidade de $\mathrm{N}$ da adubação mineral. NPK= adubação mineral recomendada. Experimento conduzido durante 62 dias em casa de vegetação no ano de 2003.

natureza do resíduo orgânico, os microrganismos presentes e as propriedades do solo são fatores chave que podem influenciar a população de nematóide e proteção de culturas (AKHTAR; MALIK, 2000). O efeito proporcionado ao solo pela adição do lodo de esgoto modificou propriedades químicas do mesmo e influenciou no aumento da atividade da microflora residente (VELAZCO,2002). Isso pode ter contribuído consideravelmente para interferir na reprodução do nematóide parasita da soja. No segundo ano do experimento, observou-se que fatores presentes no solo, tratado com doses intermediárias de lodo, continuaram a afetar a reprodução de $\boldsymbol{M}$.javanica em soja (Tabela 3). Estas concentrações do lodo, incorporadas no solo, podem ter mantido condições favoráveis à manutenção da supressividade do solo ao nematóide formador de galhas em soja.

\section{CONCLUSÕES}

O lodo de esgoto não interfere no ciclo do nematóide $\boldsymbol{H}$. glycines, porém reduz o número de ovos no interior dos cistos e a reprodução de $\boldsymbol{M}$. javanica nas raízes de soja, cultivar BRS 133.

\section{REFERÊNCIAS}

AKHTAR, M.; MALIK, A. Roles of organic soil amendments and soil organisms in the biological control of plant-parasitic nematodes: a review. Bioresource Technology, v.74, p.35-47, 2000.

ARAUJO, F.F. et al. Influência de Bacillus subtilis na eclosão, orientação e infecção de Heterodera glycines em soja. Ciência Rural, v.32, p.197-202, 2002.
BOEIRA, R.C. et al. Mineralizaçao de nitrogênio em solo tropical tratado como lodos de esgoto. Pesq agropec bras, v.37, p.1639-1647, 2002.

CETESB Aplicação de lodos de sistemas de tratamento biológico em áreas agrícolas - Critérios para projeto e operação. São Paulo : Cetesb, 1999. 32p. (Manual Técnico, Norma P.4.230).

CHEN, J. et al. Efficacy of Bacillus thuringiensis, Paecilomyces marquandii and Streptomyces costaricanus with organic amendment against Meloidogyne hapla infecting lettuce. Jounal of Nematology, v.32, p.70-77, 2000

CHEN, S. et al. Fungi associated with females and cysts of Heterodera glycines in a Florida soybean field. Journal of Nematology, v.26, p.296-3003. 1994.

CHEN, W. et al. Microbial activity and biomass in container media for predicting suppressiveness to damping-off caused by Pythium ultimum. Phytopathology, v.78, p.1447-1450, 1988.

COOK, R.N. et al. A study of the effect of nitrogen carriers on turfgrass disease. Plant Disease Reporter, v.48, p.254$255,1964$.

DIAS, W.P. et al. Quebra da resistência da cv. hartwig por população de campo do nematóide de cisto da soja (Heterodera glycines). Pesq agropec bras, v.33, p.971-974, 1998

GINTIS, B.O. et al. Fungi associated with several development stages of Heterodera glycines from Alabama field soil. Nematropica, v.13, p.181-200, 1983.

HOITINK, H.A.J.; BOEHM, M.J. Interaction between organic matter decomposition level, biocontrol agents and plant pathogens in soilborne disease. In: REUNIÃO BRASILEIRA SOBRE CONTROLE BIOLÓGICO DE DOENÇAS DE PLANTAS, 4., 1991, Campinas, SP. Anais... Campinas : EMBRAPA-CNPMA, 1991. p.63-77.

HOITINK, H.A.J. et al. Suppression of plant diseases by composts. Hortscience, v.32, p.184-187, 1997

KIM, K.D. et al. Control of Phytophthora root and crown rot of bell pepper with composts and soil amendments in the greenhouse. Applied Soil Ecology, v.5, p.169-179, 1997.

LUMSDEN, R.D. et al. Effect of composted sewage sludge on several soilborne and diseases. Phytopathology, v.73, p.15431548, 1983.

McSORLEY, R.; GALLAHER, R.N. Effect of yard waste compost on plant parasitic nematode densities in vegetable crops. Journal of Nematology, v.27, p.545-549, 1995.

MULLER, R.; GOOCH, P.S. Organic amendments in nematode control: Examination of the literature. Nematropica, v.12, p.319-326, 1982

PEREIRA, J.C.R. et al. Compostos orgânicos no controle de doenças de plantas. Revisão Anual em Proteção de Plantas, v.4, p.353-379.1996. 
RODRIGUEZ-KABANA， R. Organic and inorganic amendments to soil as nematode supressants. Journal of Nematology, v.18, p.129-135, 1986.

VELAZCO, C.L. Indução de supressividade a Phytophtora nicotiana em mudas de limão cravo com lodo de esgoto. 2002. 66f. Dissertação (Mestrado em Agronomia) - Escola Superior de Agricultura “ Luiz de Queiroz”, Universidade de São Paulo.

VIAENE, N.M.; ABAWI, G.S. Fungi parasitic on juveniles and egg masses of Meloidogyne hapla in organic soils from New York. Journal of Nematology, v.30, p.632-638, 1998 .

WANG, M. Land application of sewage sludge in China. The Science of the total environment, v.197, p.149-160, 1997.

WESTPHAL, A.; BECKER, J.O. Components of soil suppressiveness against Heterodera schachtii. Soil Biol Biochem, v.33, p.09-16, 2001.

ZHANG, W. et al. Compost-induced systemic acquired resistance in cucumber to pythium root rot and anthracnose. Phytopathology, v.86, p.1066-1070, 1996. 